\title{
Gene expression analyses associated with malignant phenotypes of metastatic sub-clones derived from a mouse oral squamous cell carcinoma Sq-1979 cell line
}

\author{
MITSUTAKA ADACHI $^{1,2}$, MASAKO MIZUNO-KAMIYA $^{1,3}$, EIJI TAKAYAMA ${ }^{1}$, HARUMI KAWAKI ${ }^{1}$, \\ TOSHIHIRO INAGAKI ${ }^{1,4}$, SHIGEKI SUMI ${ }^{1,2}$, MASAYUKI MOTOHASHI ${ }^{2}$, YASUNORI MURAMATSU ${ }^{2}$, \\ SHIN-ICHIRO SUMITOMO ${ }^{2}$, MICHIO SHIKIMORI ${ }^{5}$, YUTAKA YAMAZAKI ${ }^{6}$ and NOBUO KONDOH ${ }^{1}$
}

\begin{abstract}
Departments of ${ }^{1}$ Oral Biochemistry and ${ }^{2}$ Oral and Maxillofacial Surgery, Asahi University School of Dentistry; ${ }^{3}$ Chemistry Laboratory, Department of Management and Information Studies, Asahi University School of Business Administration, Mizuho, Gifu 501-0296; ${ }^{4}$ Department of Oral and Maxillofacial Surgery, Division of Reparative and Regenerative Medicine, Institute of Medical Science, Mie University Graduate School of Medicine, Tsu, Mie 514-8507; ${ }^{5}$ Dentistry and Oral Maxillofacial Surgery Unit, Hokuriku Central Hospital of Japan Mutual Aid Association of Public School Teachers, Oyabe, Toyama 932-8503; ${ }^{6}$ Department of Gerontology, Division of Oral Health Science, Graduate School of

Dental Medicine, Hokkaido University, Sapporo, Hokkaido 060-8586, Japan
\end{abstract}

Received September 1, 2016; Accepted October 3, 2017

DOI: $10.3892 / 01.2017 .7648$

\begin{abstract}
To elucidate the genetic events that occur during the development of OSCC, the present study established a model of oral malignancy using a mouse oral squamous cell carcinoma (OSCC) Sq-1979 cell line. Sq-1979 cells were implanted into syngeneic $\mathrm{C} 3 \mathrm{H}$ mice. Subsequently, 233 cells and metastatic sub-clones (L cells) from primary OSCC, as well as the metastasized lymph node tissues of Sq-1979-implanted mice were established. Compared with parental Sq-1979 and 233 cells, the majority of L cells exhibited a higher proliferation rate and transplantability, and conferred a lower survival rate on the implanted mice. To investigate the genetic background of $\mathrm{L}$ cells, preferentially expressed genes in L cells were identified by cDNA microarray and reverse transcription-polymerase chain reaction analyses. The expression of FYN-binding protein $(F y b)$, solute carrier family 16 member 13 (Slcl6a13), keratin 7, transmembrane portion 173 and Slc44a3 mRNAs was significantly elevated in L cells compared with that in Sq1979 and 233 cells. The mRNA expression was also evaluated in human OSCC and leukoplakia (LP) tissues. Among the 5 aforementioned mRNAs, the expression of $F Y B$ and SLC16A13 was significantly higher in OSCC than in LP tissues. Furthermore, the expression of
\end{abstract}

Correspondence to: Professor Nobuo Kondoh, Department of Oral Biochemistry, Asahi University School of Dentistry, 1851 Hozumi, Mizuho, Gifu 501-0296, Japan

E-mail: nkondoh@dent.asahi-u.ac.jp

Key words: oral squamous cell carcinoma, Sq1979 cells, C3H/HeN mice, reverse transcription-quantitative polymerase chain reaction, FYN-binding protein, solute carrier family 16 member 13
SLC16A13 mRNA was significantly elevated in highly invasive OSCCs, which were classified as grades 3 and 4 by the Yamamoto-Kohama (YK) classification of invasion, compared with those in lower grades (YK-1 and -2). The model proposed in the present study could thus describe essential marker genes for the diagnosis of oral malignancies.

\section{Introduction}

Oral squamous cell carcinoma (OSCC) is an aggressive type of cancer that can exhibit a variable degree of malignant behavior. Although advances have been made in conventional treatment, the mortality rate caused by OSCC has not markedly improved for the past several decades (1), and the biological characteristics of OSCCs are not yet well understood. The poor prognosis of patients with OSCC has now been attributed to recurrence, cervical lymph node metastasis, and resistance to radiotherapy and chemotherapy (2). An adapter-based differential display method was previously employed to elucidate the wide range of genetic events occurring during OSCC development from pre-cancerous leukoplakia (LP) (3). A comprehensive gene expression profile was also generated to discriminate between LPs and OSCCs (4). Following therapy, metastasis has proven to be a main cause of local relapse in patients with OSCC. Of the conventional staging and grading systems that are used for the assessment of OSCC tissues, the Yamamoto-Kohama (YK) mode of invasion (5) system can be largely associated with prognosis, particularly with regard to lymph node metastases $(6,7)$. The YK mode of invasion was devised from the grading of the mode of invasion originally described by Jacobson et al (8); in this histological grading, grade 4 is sub-classified into grades $4 \mathrm{C}$ and $\mathrm{D}$, whereas evaluation of other grades is the same as defined by Jacobson's classifier (8). Using primary OSCCs, molecular events associated with the 
YK mode of invasion were evaluated previously and prediction models for the invasion status were constructed (9).

Clinical specimens generally originate from different genetic backgrounds, which may have considerable influence on the variation of gene effects. Consequently, there is little opportunity to directly compare primary and metastatic OSCC specimens from the same patient. As an alternative approach to elucidate genetic events intimately associated with the metastatic potentials of OSCC cells, the establishment of metastatic sub-clones (L cells) was attempted from the primary mouse OSCC Sq-1979 cell line in the present study. Next, comprehensive gene expression was compared between Sq-1979 and L cells to identify differentially expressed mRNAs. Our previous studies demonstrated that the expression of certain mRNAs, such as keratin1 and transglutaminase 3, exhibit continual changes from pre-cancerous to cancerous tissues and to further malignant OSCCs $(4,9)$. In the present study, it was revealed that the expression of certain marker mRNAs could be an index for evaluating the histological grading of precancerous and OSCC tissues obtained from patients.

\section{Materials and methods}

Experimental animals. Male, 5-week-old, $160 \mathrm{C} 3 \mathrm{H} / \mathrm{HeN}$ mice were purchased from Chubu Kagaku Shizai Co., Ltd. (Nagoya, Japan) and mice were housed one per cage in a room at $22-23^{\circ} \mathrm{C}$ under standard atmospheric pressure with a $12 \mathrm{~h}$ light/dark cycle with ad libitum access to Oriental MF solid chow (Oriental Yeast Co., Tokyo, Japan) and water; the domestication was continued for 2 weeks before the start of each experiment. The present study was approved by the Animal Ethics Committee of Asahi University (Mizuho, Gifu, Japan).

Cells and establishment of sub-clones. The C3H mouse OSCC Sq1979 cell line was obtained from the Riken BioResource Center (Ibaraki, Japan). Cells were grown at $37^{\circ} \mathrm{C}$ in $5 \% \mathrm{CO}_{2}$ in Eagle's minimum essential medium (E-MEM; Wako Pure Chemical Industries, Ltd., Osaka, Japan) supplemented with $10 \%$ fetal bovine serum (FBS; Nichirei Biosciences, Inc., Tokyo, Japan) and $1 \%$ penicillin/streptomycin $(10,000 \mathrm{U} / \mathrm{ml}$ penicillin, 10,000 $\mu \mathrm{g} / \mathrm{ml}$ streptomycin; Gibco; Thermo Fisher Scientific Inc., Waltham, MA, USA). A total of 1x107 Sq-1979 cells were suspended in $0.1 \mathrm{ml}$ saline, then subcutaneously injected into the posterior neck area of five 7-week-old male $\mathrm{C} 3 \mathrm{H} / \mathrm{HeN}$ mice. After 3 months, metastasized regional lymph nodes were dissected into E-MEM supplemented with $10 \%$ FBS and minced to isolate attached cells. Next, metastasized sub-clones, termed L2-3, L3-5, L5-11, L6-8 and L6-9 cells, were isolated by a limiting serial-dilution method, as described previously (10). Using the same procedure, for later experiments, 233-1 and 233-11 independent cell clones were isolated from primary OSCC tissues of Sq-1979-implanted mice.

Proliferation properties. To examine the cell proliferation rate in vitro, $2 \times 10^{4}$ cells were seeded into each well of a 6 -well plate. Doubling times (DTs) were calculated by counting cell numbers using a Burker-Turk hemocytometer after 24, 48, 72 and $96 \mathrm{~h}$. To evaluate the in vivo proliferation of OSCC cells, $1 \times 10^{6}-1 \times 10^{7}$ cells suspended in $0.1 \mathrm{ml}$ saline were injected subcutaneously into the lateroabdominal area of 5 male, 6 -week-old, $\mathrm{C} 3 \mathrm{H} / \mathrm{HeN}$ mice. The tumor volume was measured using a digital caliper, and calculated as follows: Tumor volume $=($ major axis $) \times(\text { minor axis })^{2} \times 0.52$, as described previously (11). Tumor DT estimates used the first and last available tumor volumes $\left(\mathrm{V}_{\mathrm{o}}\right.$ and $\left.\mathrm{V}_{\mathrm{i}}\right)$, the time interval $\mathrm{T}_{\mathrm{i}}$ (in days) between the two exams, and the following formula: $\mathrm{DT}=\log _{2} \mathrm{~T}_{\mathrm{i}} /\left(\log \mathrm{V}_{\mathrm{i}}-\log \mathrm{V}_{\mathrm{o}}\right)$, as described previously (12).

Transplantability. To examine the transplantability, $1 \times 10^{4}$, $1 \times 10^{5}, 1 \times 10^{6}$ or $1 \times 10^{7} \mathrm{Sq}-1979, \mathrm{Sq}-1979-1,23-1,233-11, \mathrm{~L} 2-3$, L3-5, L5-11, L6-8 and L6-9 cells were injected subcutaneously into the lateroabdominal area of male, 6-week-old, $\mathrm{C} 3 \mathrm{H} / \mathrm{HeN}$ mice $(n=5$ per experiment). After 1 month, mice bearing tumors (>4 mm) were counted as positive animals. Transplantability was defined as: Transplantability=positive animals/total animals $\mathrm{x} 100$.

Survival rates. To examine survival rates, $1 \times 10^{6} \mathrm{Sq}-1979-1$, 23-1, 233-11, L2-3, L3-5, L5-11, L6-8 and L6-9 cells were injected subcutaneously into the lateroabdominal area of male, 6-week-old, $\mathrm{C} 3 \mathrm{H} / \mathrm{HeN}$ mice ( $\mathrm{n}=5$ per experiment). 5 PBS-injected mice were observed as controls. The survival time (days) was determined. Mice were considered to have survived until they failed to eat or drink for $24 \mathrm{~h}$, or until tumors reached a maximum volume of $3510 \mathrm{~mm}^{3}$ at which they interfered with locomotion to eat or drink, at which point they were euthanized by cervical dislocation, in accordance with guidelines set out by Workman et al (13).

RNA extraction and microarray analysis. RNA extraction was performed using ISOGEN (Nippon Gene Co., Ltd., Tokyo, Japan), according to the manufacturer's protocols. Total RNA was extracted from Sq-1979 and L5-11 cells. cDNA microarray analysis was performed (Oncomics, Nagoya, Japan) using the Superscript G3 mouse GE Microarray 60K kit (Agilent Technologies, Inc., Santa Clara, CA, USA). To ensure the reliability of the data, genes were considered to be differentially expressed using the following threshold criteria: $\mathrm{P}<0.001$ (using Student's t-test) and fold-change $>2.0$.

CDNA samples of precancerous and OSCC tissues. cDNA samples from 18 patients with OSCC (median age, 65 years; 7 male, 11 female; age range, 38-91 years) and 18 patients with LP (median age, 72 years; age range, 57-98 years) were incorporated into the present study. Tissue samples that had been surgically resected in the Dental Hospital of Hokkaido University (Sapporo, Hokkaido, Japan) between February 1998 and April 2004, and cDNA synthesis had already been performed, as described previously (9). All procedures were undertaken after written informed consent had been obtained from each patient, and the study adhered to the ethical guidelines of the dental hospital of the Hokkaido University School of Dentistry (Sapporo, Japan). The present study was also approved by the Ethics Committee of Asahi University (no. 27007).

Reverse transcription-quantitative polymerase chain reaction (RT-qPCR). Whole-cell RNA extraction and quantitative PCR was performed as previously described (4). Primer sequences were designed by Primer Express software (version 2; Applied 
Table I. Polymerase chain reaction primers used in this experiment.

\begin{tabular}{|c|c|c|}
\hline Symbol & Forward $\left(5^{\prime}-3^{\prime}\right)$ & Reverse (5'-3') \\
\hline \multicolumn{3}{|l|}{ Mouse } \\
\hline$K r t 7$ & AACAGCCGCTCCCTGGACTTG & GGTCATCCCCGTGCTTCCC \\
\hline Slc16a13 & GGCTTCCTCAACCCTGGTAGTCC & GCCGATACTCTCGATCATCTGCAC \\
\hline Slc44a3 & ATGGATCGTCGGAGAAACCGTAC & СССТАТСТCACAATGGGCTGGAG \\
\hline$F y b$ & AAGTTGCAGGACAAAGCTCGCCT & TCCTCGTAGGTAGGTTTCGCTGCC \\
\hline Tmem173 & CCTCCGTACTGTCCCAAGAGCCA & CCAACCATTGAAGGAAGGCTCAG \\
\hline Rps5 & AGAAGACTCAACACGCATTGGGC & GCACTCAGCGATGGTCTTGATGT \\
\hline \multicolumn{3}{|l|}{ Human } \\
\hline KRT7 & GACATCTTTGAGGCCCAGATTGC & CTGTGCGGCGGTTAATTTCATC \\
\hline SLC16A13 & TCCTGGATCGCCTCCATAGGAATC & AGGAAGTAGCAAAAGAGGCGAGCA \\
\hline SLC44A3 & TTTGGCTATGACAGCTTTGGCAA & TGCGGTTGAGCTGCGTACCTTT \\
\hline$F Y B$ & CAGGAAGATCCACTAAAGGAGGCC & CCCCGTGTTATATTTCGCCATGAG \\
\hline TMEM173 & AAGGGAATTTCAACGTGGCCAT & ATATACAGCCGCTGGCTCACTGC \\
\hline RPS5 & GAGCGCCTCACTAACTCCATGATGA & CACTGTTGATGATGGCGTTCACCA \\
\hline
\end{tabular}

Krt7, keratin7; Slc16a13, solute carrier family 16 member 13; Fyb, FYN-binding protein; Tmem173, transmembrane protein 173; RPS5, ribosomal protein S5.

Biosystems; Thermo Fisher Scientific, Inc.). The primers used are summarized in Table I. Each expression level of mRNA was normalized to ribosomal protein S5 (RPS5).

Statistical analysis. Data are expressed as the mean \pm standard deviation. A Mann-Whitney U test or Student's t-test (for microarray analysis) was applied to determine the significance of differences between two groups using Excel Statistics (2008; version 1) (SSRI Inc., Tokyo, Japan). $\mathrm{P}<0.05$ was considered to indicate a statistically significant difference.

\section{Results}

Proliferation properties of Sq-1979-derived sub-clones. To evaluate the proliferation properties of OSCC sub-clones, DTs in vitro and in vivo were compared. As shown in Table II, the DTs of tumor volume for Sq-1979 and 233 cells had a mean value of 14.7 and 14.8 days, respectively, whereas that of L cells was significantly shorter, at 8.3 days. The in vitro population DT of Sq-1979 and 233 cells was a mean of 11.4 and $14.4 \mathrm{~h}$, respectively, which was shorter than in vivo and similar to that of L cells (mean, $14.4 \mathrm{~h}$ ). These results indicated that $\mathrm{L}$ cells have a specific property that is advantageous for in vivo cell proliferation.

Transplantability and survival rates. As shown in Table III, when $1 \times 10^{5}$ cells were inoculated into mice, the transplantability of the majority of L cells, including L3-5, L5-11 and L6-9 cells, ranged between 20 and $100 \%$; however, with the exception of 233-11 cells, parental cells and non-metastasized sub-clones, including Sq-1979, Sq-1979-1 and 233-1 cells, were not transplantable, even though mice were inoculated with the same number of cells. When mice were inoculated with $1 \times 10^{6}$ cells, all the cell types exhibited substantial transplantability of $>60 \%$. These results demonstrated that the
Table II. Growth properties of Sq1979 cells and the sub-clones.

\begin{tabular}{lcc}
\hline & \multicolumn{2}{c}{ Doubling time } \\
\cline { 2 - 3 } Cells & In vivo, days & In vitro, $\mathrm{h}$ \\
\hline Original cells & & \\
Sq-1979 & $20.1 \pm 9.8$ & $10.1 \pm 0.2$ \\
Sub-clones & & \\
Sq-1979-1 & $11.6 \pm 7.3^{\mathrm{a}}$ & $11.0 \pm 3.3$ \\
Sq-1979-2 & 14.8 & $11.8 \pm 1.0$ \\
Sq-1979-3 & 12.3 & $11.6 \pm 0.8$ \\
Primary tumors & & \\
233-1 & $12.0 \pm 5.8$ & $12.7 \pm 0.5$ \\
233-11 & $17.5 \pm 6.9$ & $16.0 \pm 4.8$ \\
Lymph node metastases & & \\
L2-3 & $8.3 \pm 5.6^{\mathrm{b}}$ & $12.1 \pm 0.3^{\mathrm{a}}$ \\
L3-5 & $8.1 \pm 3.5^{\mathrm{b}}$ & $11.6 \pm 1.1^{\mathrm{a}}$ \\
L5-11 & $7.3 \pm 5.7^{\mathrm{b}}$ & $15.4 \pm 1.2^{\mathrm{a}}$ \\
L6-8 & $4.4 \pm 0.8^{\mathrm{b}}$ & $14.1 \pm 0.4^{\mathrm{a}}$ \\
L6-9 & $5.6 \pm 1.7^{\mathrm{b}}$ & $18.6 \pm 2.5^{\mathrm{a}}$ \\
\end{tabular}

$\mathrm{n}=3$ (except for Sq1979-2 and -3 , where $\mathrm{n}=1$ ). Data are presented as the mean \pm standard deviation. ${ }^{\mathrm{a}} \mathrm{P}<0.05$; ${ }^{\mathrm{b}} \mathrm{P}<0.01 \mathrm{vs}$. Sq1979 cells (Mann-Whitney U test).

majority of L cells exhibited markedly higher transplantability than parental Sq-1979 cells and the non-metastatic sub-clones, including Sq-1979-1 and 233-11 cells.

The present study also examined the mean survival time of tumor-burdened mice. As shown in Table IV, mice transplanted with L5-11 and L6-9 cells exhibited significantly 
Table III. Transplantability of oral squamous cell carcinoma cells.

\begin{tabular}{lccrc}
\hline & \multicolumn{4}{c}{ Transplantability, \% } \\
\cline { 2 - 5 } Cells/body & $10^{4}$ & $10^{5}$ & $10^{6}$ & $10^{7}$ \\
\hline Sq-1979 & NP & 0 & 88 & 98 \\
Sq-1979-1 & NP & 0 & 100 & 92 \\
233-1 & NP & 0 & 60 & 88 \\
233-11 & NP & 20 & 100 & 100 \\
L2-3 & 0 & 0 & 83 & NP \\
L3-5 & 0 & 20 & 79 & NP \\
L5-11 & 40 & 100 & 100 & NP \\
L6-8 & NP & NP & 100 & NP \\
L6-9 & 100 & 80 & 100 & NP \\
\hline
\end{tabular}

Cells were injected subcutaneously into mice $(n>5)$. The mice bearing tumor nodules larger than $4 \mathrm{~mm}$ were designated as positive animals NP, not performed.

Table IV. Survival rates of tumor-transplanted mice.

\begin{tabular}{lc}
\hline Cells & Mean survival time \pm SD, days \\
\hline Sq-1979-1 & $138 \pm 39$ \\
$233-1$ & $146 \pm 24$ \\
L2-3 & $99 \pm 18$ \\
L3-5 & $113 \pm 25$ \\
L5-11 & $81 \pm 8^{\mathrm{a}}$ \\
L6-8 & 57 \\
L6-9 & $60 \pm 4^{\mathrm{b}}$
\end{tabular}

$\mathrm{n}=5$ (except for L6-8, where $\mathrm{n}=1$ ). ${ }^{\mathrm{a}} \mathrm{P}<0.05$, ${ }^{\mathrm{b}} \mathrm{P}<0.01$ vs. Sq1979-1 (Mann-Whitney U test). Control (untransplanted) mice survived $>1$ year (data not shown). SD, standard deviation.

shorter survival times than those transplanted with Sq1979-1, 233-1, L2-3 and L3-5. The mice transplanted with L6-8 cells also exhibited shorter survival times. These results indicated that the majority of $\mathrm{L}$ cells possess highly malignant and advanced phenotypes compared with parental Sq-1979 cells and their non-metastatic sub-clones.

Isolation of mRNAs predominantly expressed in L cells. To clarify the identity of expressed genes associated with the malignant phenotypes of L cells, comprehensive gene expression of L5-11 and Sq-1979-1 cells was compared using microarray analysis. Of the $60 \mathrm{mRNAs}$ more predominantly expressed in L5-11 cells ( $\geq 3$-fold) than in Sq-1979-1 cells (data not shown), the expression among Sq-1979, 233 and L cells was further verified using RT-PCR analysis. Consequently, 5 mRNAs were focused on, including keratin 7 (Krt7), FYN binding protein $(F y b)$, solute carrier family 16 member 13 (Slc16a13), transmembrane protein 173 (Tmem173) and solute carrier family 44 member 3 (Slc44a3) mRNA. As shown in Fig. 1, the expression

Table V. Clinicopathological features of 18 leukoplakia patients.

\begin{tabular}{lc}
\hline Characteristic & Patients, $\mathrm{n}$ \\
\hline Total & 18 \\
Site & \\
Tongue & 8 \\
Gingiva & 5 \\
Buccal mucosa & 3 \\
Other & 2 \\
Histology & \\
Hyperplasia & 3 \\
Mild dysplasia & 3 \\
Moderate dysplasia & 3 \\
Severe dysplasia & 6 \\
Unclassified & 3 \\
\hline
\end{tabular}

Table VI. Clinicopathological features of 18 patients with oral squamous cell carcinoma.

\begin{tabular}{|c|c|}
\hline Characteristic & Patients, $\mathrm{n}$ \\
\hline Total & 18 \\
\hline \multicolumn{2}{|l|}{ Sex } \\
\hline Male & 13 \\
\hline Female & 5 \\
\hline \multicolumn{2}{|l|}{ Site } \\
\hline Tongue & 9 \\
\hline Gingiva (upper) & 3 \\
\hline Gingiva (lower) & 3 \\
\hline Buccal mucosa & 2 \\
\hline Floor of mouth & 1 \\
\hline \multicolumn{2}{|l|}{$\mathrm{T}$ classification } \\
\hline $\mathrm{T} 1$ & 6 \\
\hline $\mathrm{T} 2$ & 5 \\
\hline $\mathrm{T} 3$ & 3 \\
\hline $\mathrm{T} 4$ & 4 \\
\hline \multicolumn{2}{|l|}{ Metastasis } \\
\hline Negative & 15 \\
\hline Positive & 3 \\
\hline \multicolumn{2}{|l|}{ Mode of invasion } \\
\hline YK-1 & 2 \\
\hline YK-2 & 7 \\
\hline YK-3 & 4 \\
\hline $\mathrm{YK}-4 \mathrm{C}$ & 2 \\
\hline YK-4D & 2 \\
\hline Unidentified & 1 \\
\hline
\end{tabular}

T, tumor; YK, Yamamoto-Kohama.

of $K r t 7$ mRNA was markedly lower in Sq-1979-1, -2, -3, 233-1 and -11 cells compared with in any other L cells, including L2-3, 
Krt-7

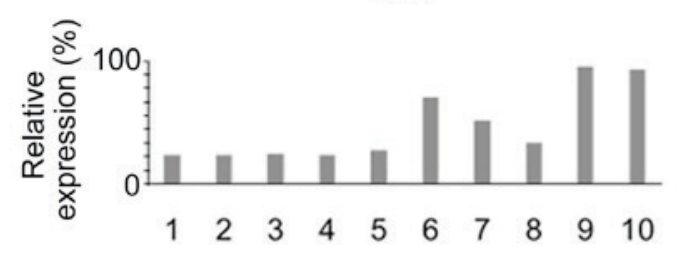

S/c16a13
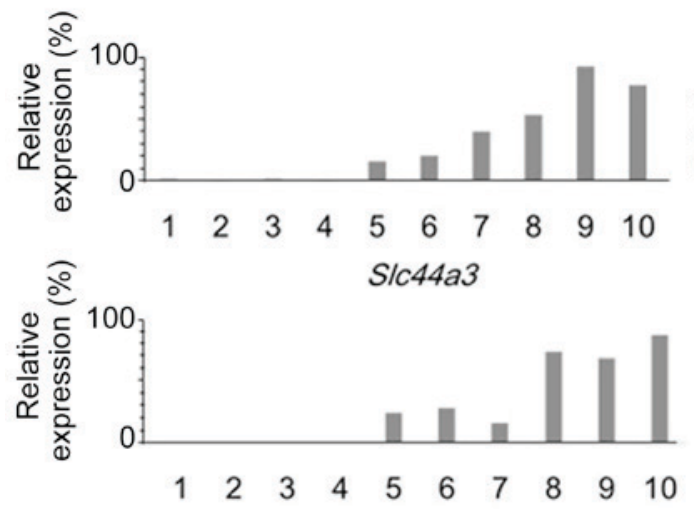

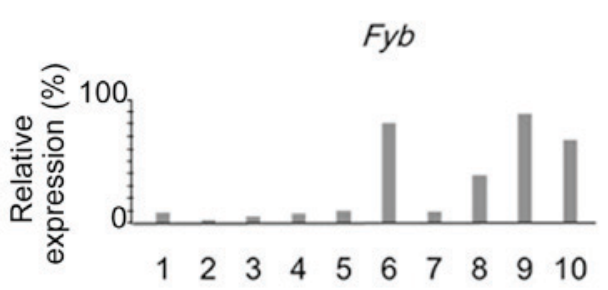

Tmem173

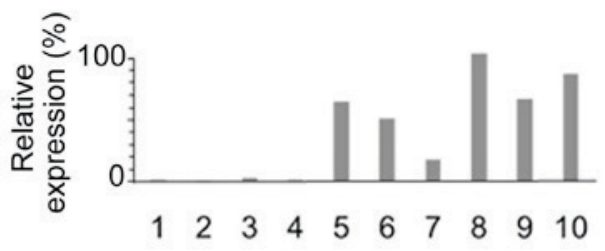

\begin{tabular}{llll}
$1:$ & Sq-1979-1 & $6:$ & L2-3 \\
$2:$ & Sq-1979-2 & $7:$ & L3-5 \\
$3:$ & Sq-1979-3 & $8:$ & L5-11 \\
$4:$ & $233-1$ & $9:$ & L6-8 \\
$5:$ & $233-11$ & $10:$ & L6-9 \\
\hline
\end{tabular}

Figure 1. Expression of Fyb, Slc16a13, Krt7, Temem173 and Slc44a3 mRNAs in Sq1979 and the sub-clones. Relative expression levels, expressed as percentages, are in ordinate, and cells are in abscissa. Fyb, FYN-binding protein; Slc16a13, solute carrier family 16 member 13; Krt7, keratin 7; Temem173, transmembrane protein 173.
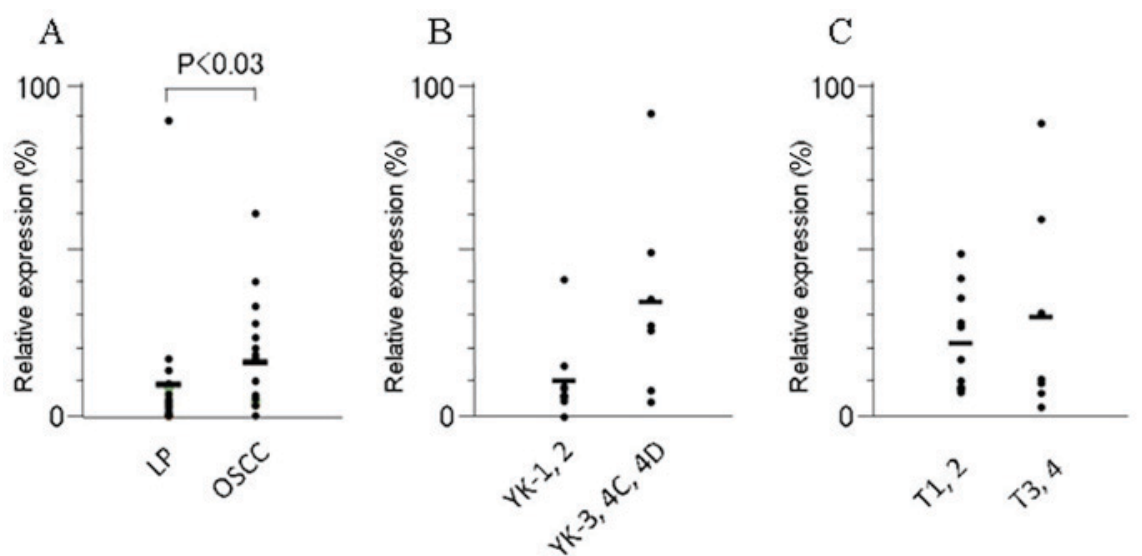

Figure 2. Expression of FYN-binding protein mRNA in OSCC and LP tissues. Relative expression levels, expressed as percentages, are in ordinate, and cells are in abscissa. The expression levels were compared between (A) LP and OSCC tissues, (B) OSCCs classified as being in lower YK grades and those in the higher grades and (C) OSCCs classified as being in lower T grades and those in the higher grades, respectively. The dash denotes the mean level. The results are also summarized in Table VII. OSCC, oral squamous cell carcinoma; LP, leukoplakia; YK, Yamamoto-Kohama; T, tumor.

3-5, 5-11, 6-8 and 6-9 cells. The expression of $F y b$ mRNA was also lower in Sq-1979-1, -2, -3, 233-1 and -11 cells compared with L cells, including L2-3, 5-11, 6-8 and 6-9 cells. The expression of Slcl6a13, Temem173 and Slc44a3 mRNA was almost undetectable in the three Sq-1979 sub-clones and 233-1 cells, whereas the expression was high overall in all $5 \mathrm{~L}$ cells. The results of the present study demonstrated that the expression of Krt7, Fyb, Slcl6a13, Tememl73 and Slc44a3 mRNAs was significantly higher in metastatic sub-clones, including $5 \mathrm{~L}$ cell types, than in original Sq-1979 and primary 233 cells.

Expression of mRNAs in human OSCC and LP tissues. To further evaluate the expression of these 5 mRNAs among oral malignancies, RT-PCR analyses using cDNAs derived from $18 \mathrm{LP}$ (Table V) and 18 OSCC (Table VI) tissues were performed. The main clinicopathological characteristics of each patient are summarized in the Tables V and VI, respectively. The expression of FYB and SLC16A13 mRNA was significantly higher in OSCCs than in LPs tissues $(\mathrm{P}<0.03$ and $\mathrm{P}<0.04$, respectively) (Figs. 2 and 3; Table VII). Furthermore, among the OSCCs, the expression of SLC16A13 mRNA was significantly elevated, in accordance with the acquisition of invasion status; this expression was significantly higher in OSCCs of higher YK grades (YK3-4D) than in those of lower grades (YK1 and 2) $(\mathrm{P}<0.02)$. The level of KRT7, SLC44A3 and TEMEM173 mRNA did not differ significantly between human OSCC and LP tissues, nor 
Table VII. Association between clinicopathological factors and mRNA expression among oral squamous cell carcinoma ( $\mathrm{n}=18)$ and leukoplakia $(\mathrm{n}=18)$ tissues.

\begin{tabular}{|c|c|c|c|c|c|c|}
\hline \multirow[b]{2}{*}{ Factors } & \multirow[b]{2}{*}{ Patients, $\mathrm{n}$} & \multicolumn{5}{|c|}{ P-value (Mann-Whitney U test) } \\
\hline & & $F Y B$ & SLC16A13 & TEMEM173 & SLC $44 A 3$ & KRT-7 \\
\hline OSCC/leukoplakia & & $<0.03^{\mathrm{a}}$ & $<0.04^{\mathrm{a}}$ & $<1.00$ & $<0.12$ & $<0.28$ \\
\hline OSCC & 18 & & & & & \\
\hline Leukoplakia & 18 & & & & & \\
\hline T classification & & $<1.00$ & $<0.74$ & $<0.23$ & $<0.23$ & $<0.14$ \\
\hline $\mathrm{T} 1-2$ & 11 & & & & & \\
\hline T3-4 & 7 & & & & & \\
\hline Mode of invasion & & $<0.07$ & $<0.02^{\mathrm{a}}$ & $<0.25$ & $<1.00$ & $<0.17$ \\
\hline YK1-2 & 9 & & & & & \\
\hline YK3-4D & 8 & & & & & \\
\hline
\end{tabular}

${ }^{\mathrm{a}} \mathrm{P}<0.05 . K R T 7$, keratin7; SLC16A13, solute carrier family 16 member 13; FYB, FYN-binding protein; TMEM173, transmembrane protein 173.
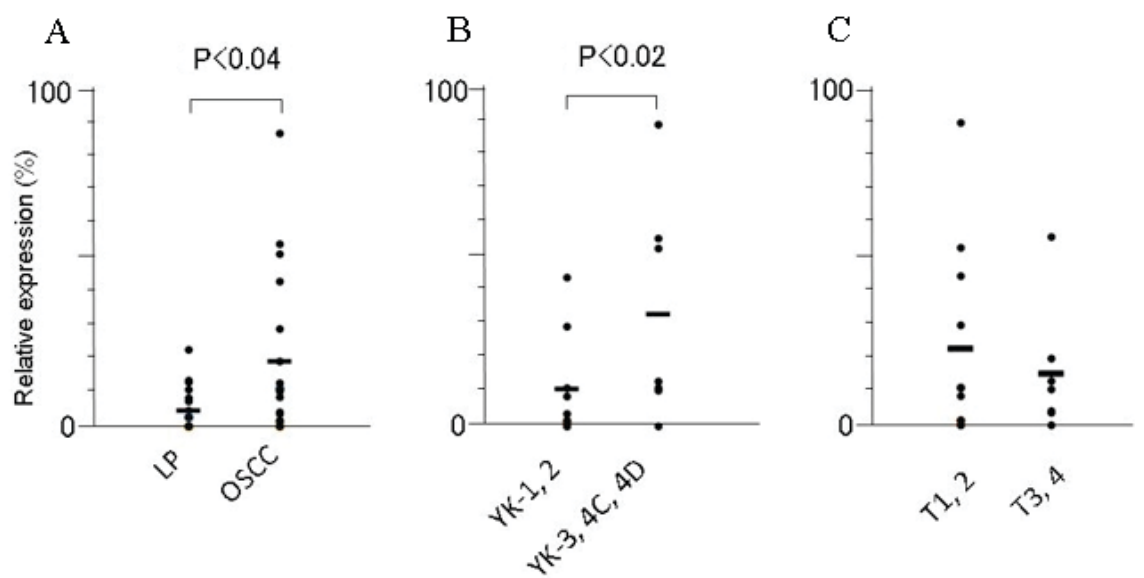

Figure 3. Expression of solute carrier family 16 member 13 mRNA in OSCC and LP tissues. Relative expression levels, expressed as percentages, are in ordinate, and cells are in abscissa. The expression levels were compared between (A) LP and OSCC tissues, (B) OSCCs classified as being in lower YK grades and those in the higher grades, and (C) OSCCs classified as being in lower T grades and those in the higher grades. The dash denotes the mean level. These results are also summarized in Table VII. LP, leukoplakia; OSCC, oral squamous cell carcinoma; YK, Yamamoto-Kohama; T, tumor.

between OSCCs in different YK grades (Table VII). The expression of none of these $5 \mathrm{mRNAs}$ was regulated in association with tumor size ( $\mathrm{T}$ stage) according to the tumor-node-metastasis classification of the Union for International Cancer Control (14) among OSCC tissues (Table VII).

\section{Discussion}

The present study established metastatic sub-clones (L cells) from mouse oral squamous Sq-1979 cells. The aggressive nature of the L cells was demonstrated by their higher in vivo proliferation rates and transplantability, and the lower survivability of tumor-burdened mice. Using these models, preferentially expressed genes were screened for in L cells, and 5 mRNAs, Fyb, Slcl6al3, Krt-7, Temem173 and Slc44a3, were isolated.

Of these mRNAs, FYB was significantly elevated in aggressive human OSCC tissues compared with that in LPs. FYB is an active component of FYN kinase (12). Since FYN kinase is known to modulate the epithelial-mesenchymal transition (15) and stimulate proliferation of OSCC cells (16), FYB can modulate the progression from dysplasia to invasive OSCC via FYN kinase activity. FYB is expressed in $\mathrm{T}$ cells, myeloid cells and platelets, in which it regulates receptor-mediated integrin activation and adhesion (17). FYB enhances programmed cell death receptor-1 expression in cluster of differentiation 8-positive $\mathrm{T}$ cells and reduces the cytotoxic $\mathrm{T}$ lymphocyte cytotoxicity (18). Although the manner in which FYB products from OSCC are able to affect $\mathrm{T}$ lymphocytes is yet to be investigated, FYB may promote tumor progression by reducing antitumor immunity in OSCC patients.

SLC16A13, encoding a monocarboxylic acid transporter, has been identified as a novel candidate gene for type 2 diabetes, with a possible role in triacylglycerol metabolism (19). However, to the best of our knowledge, no previous study has reported this gene as being associated with tumor etiology. Notably, the present study demonstrated that the expression 
of SLC16A13 mRNA was significantly higher in OSCCs than it was in LPs. Furthermore, the expression of SLC16A13 was significantly higher in highly invasive OSCCs classified as being of higher YK grades (YK3-4D) than in those of lower grades (YK1 and 2). The comparison between OSCC groups using the YK classification almost completely matches the comparison made between grades 3-4 and 1-2 for the mode of invasion described by Jacobson et al (8). Hence, the expression of SLC16A13 mRNA in highly invasive OSCCs could also be validated by Jacobson's classification. Since mode of invasion described by Yamamoto et al (5) and Jacobson et al (8) is largely associated with the incidence of lymph node metastasis (5-7,8), the expression of SLC16A13 mRNA could confer important predictive values for metastases and recurrence risks for OSCC patients.

In the present study, the expression of KRT7 mRNA was not significantly higher in OSCCs than that in LPs; its expression is known to be activated in several malignancies, including gastric cancer (20), cervical low-grade squamous intraepithelial lesions (21), lung cancer (22), urothelial carcinoma (23), esophageal carcinoma (24) and other squamous cell carcinomas $(25)$.

In conclusion, the present study identified marker genes using mouse OSCC sub-clones originating from regional lymph node metastasis. Using the same approach, it may be possible to establish variable malignant phenotypes from other distal metastases (e.g., of the lung) of primary mouse OSCC cells. Such an approach could provide further information on the molecular basis of progressive OSCCs.

\section{Acknowledgements}

The present study was supported in part by the Grants-in-Aid for Scientific Research from the Japan Society for the Promotion of Science (grant no. 26463055).

\section{References}

1. Gupta S, Kong W, Peng Y, Miao Q and Mackillop WJ: Temporal trends in the incidence and survival of cancers of the upper aerodigestive tract in Ontario and the United States. Int J Cancer 125: 2159-2165, 2009.

2. Leemans CR, Braakhuis BJ and Brakenhoff RH: The molecular biology of head and neck cancer. Nat Rev Cancer 11: 9-22, 2011.

3. Ohkura S, Kondoh N, Hada A, Arai M, Yamazaki Y, Sindoh M, Takahashi M, Matsumoto I and Yamamoto M: Differential expression of the keratin-4, $-13,-14,-17$ and transglutaminase 3 genes during the development of oral squamous cell carcinoma from leukoplakia. Oral Oncol 41: 607-613, 2005.

4. Kondoh N, Ohkura S, Arai M, Hada A, Ishikawa T, Yamazaki Y, Shindoh M, Takahashi M, Kitagawa Y, Matsubara O and Yamamoto M: Gene expression signatures that can discriminate oral leukoplakia subtypes and squamous cell carcinoma. Oral Oncol 43: 455-462, 2007.

5. Yamamoto E, Kohama G, Sunakawa H, Iwai M and Hiratsuka H: Mode of invasion, bleomycin sensitivity, and clinical course in squamous cell carcinoma of the oral cavity. Cancer 51: 2175-2180, 1983.

6. Kaihara T, Kusaka T, Kawamata H, Oda Y, Fujii S, Morita K, Imura J and Fujimori T: Decreased expression of E-cadherin and Yamamoto-Kohama's mode of invasion highly correlates with lymph node metastasis in esophageal squamous cell carcinoma. Pathobiology 69: 172-178, 2001.

7. Nakayama A, Ogawa A, Fukuta Y and Kudo K: Relation between lymphatic vessel diameter and clinicopathologic parameters in squamous cell carcinomas of the oral region. Cancer 86: 200-206, 1999.
8. Jacobson PA, Enoroth CM, Killander D, Moberger G and Mårtensson B: Histologic classification and grading of malignancy in carcinomaof the larynx. Acta Radiol Ther Phys Biol 12: $1-8,1973$

9. Kondoh N, Ishikawa T, Ohkura S, Arai M, Hada A, Yamazaki Y, Kitagawa Y, Shindoh M, Takahashi M, Ando T, et al: Gene expression signatures that classify the mode of invasion of primary oral squamous cell carcinomas. Mol Carcinog 47: 744-756, 2008

10. Freshney RIan: Culture of animal cells: A manual of basic technique and specialized applications 6th edition. Hoboken, N.J. Wiley-Blackwell: pp208-211, 2010.

11. Klopp AH, Zhang Y, Solley T, Amaya-Manzanares F, Marini F, Andreeff M, Debeb B, Woodward W, Schmandt R, Broaddus R, et al: Omental adipose tissue-derived stromal cells promote vascularization and growth of endometrial tumors. Clin Cancer Res 18: 771-782, 2012.

12. da Silva AJ, Li Z, de Vera C, Canto E, Findell P and Rudd CE: Cloning of a novel T-cell protein FYB that binds FYN and SH2-domain-containing leukocyte protein 76 and modulates interleukin 2 production. Proc Natl Acad Sci USA 94: 7493-7498, 1997.

13. Workman P, Aboagye EO, Balkwill F, Balmain A, Bruder G, Chaplin DJ, Double JA, Everitt J, Farningham DA, Glennie MJ, et al: Guidelines for the welfare and use of animals in cancer research. Br J Cancer 102: 1555-1577, 2010.

14. Brierley JD, Gospodarowicz MK and Wittekind C (eds): TNM classification of malignant tumours, 8th edition. New York, Wiley-Blackwell: pp272, 2016.

15. Lewin B, Siu A, Baker C, Dang D, Schnitt R, Eisapooran P and Ramos DM: Expression of Fyn kinase modulates EMT in oral cancer cells. Anticancer Res 30: 2591-2596, 2010.

16. Li X, Yang Y, Hu Y, Dang D, Regezi J, Schmidt BL, Atakilit A, Chen B, Ellis D and Ramos DM: Alphavbeta6-Fyn signaling promotes oral cancer progression. J Biol Chem 278: 41646-41653, 2003.

17. Engelmann S, Togni M, Thielitz A, Reichardt P, Kliche S, Reinhold D, Schraven B and Reinhold A: T cell-independent modulation of experimental autoimmune encephalomyelitis in ADAP-deficient mice. J Immunol 191: 4950-4959, 2013.

18. Li C, Li W, Xiao J, Jiao S, Teng F, Xue S, Zhang C, Sheng C, Leng Q, Rudd CE, et al: ADAP and SKAP55 deficiency suppresses PD-1 expression in CD8+ cytotoxic T lymphocytes for enhanced anti-tumor immunotherapy. EMBO Mol Med 7: 754-769, 2015.

19. SIGMA Type 2 Diabetes Consortium, Williams AL, Jacobs SB, Moreno-Macías H, Huerta-Chagoya A, Churchhouse C, Márquez-Luna C, García-Ortíz H, Gómez-Vázquez MJ, Burtt NP, et al: Sequence variants in SLC16A11 are a common risk factor for type 2 diabetes in Mexico. Nature 506: 97-101, 2014.

20. Huang B, Song JH, Cheng Y, Abraham JM, Ibrahim S, Sun Z, Ke X and Meltzer SJ: Long non-coding antisense RNA KRT7-AS is activated in gastric cancers and supports cancer cell progression by increasing KRT7 expression. Oncogene 35: 4927-4936, 2016.

21. Paquette C, Mills AM and Stoler MH: Predictive value of cytokeratin 7 immunohistochemistry in cervical low-grade squamous intraepithelial lesion as a marker for risk of progression to a high-grade lesion. Am J Surg Pathol 40: 236-243, 2016.

22. Si LL, Lv L, Zhou WH and Hu WD: Establishment and identification of human primary lung cancer cell culture in vitro. Int $\mathrm{J}$ Clin Exp Pathol 8: 6540-6546, 2015.

23. Chatterjee D, Das A and Radotra BD: Invasive micropapillary carcinoma of urinary bladder: A clinicopathological study. Indian J Pathol Microbiol 58: 2-6, 2015.

24. Sano M, Aoyagi K, Takahashi H, Kawamura T, Mabuchi T, Igaki H, Tachimori Y, Kato H, Ochiai A, Honda H, et al: Forkhead box A1 transcriptional pathway in KRT7-expressing esophageal squamous cell carcinomas with extensive lymph node metastasis. Int J Oncol 36: 321-330, 2010.

25. Regauer S, Beham A and Mannweiler S: CK7 expression in carcinomas of the Waldeyer's ring area. Hum Pathol 31: 1096-1101, 2000 . 